\title{
Droughts threaten high-altitude Himalayan forests
}

Timberlines in the region are shifting downslope, bucking trend seen on other mountain ranges.

Jane Qiu

27 January 2015

An article by Scientific American.

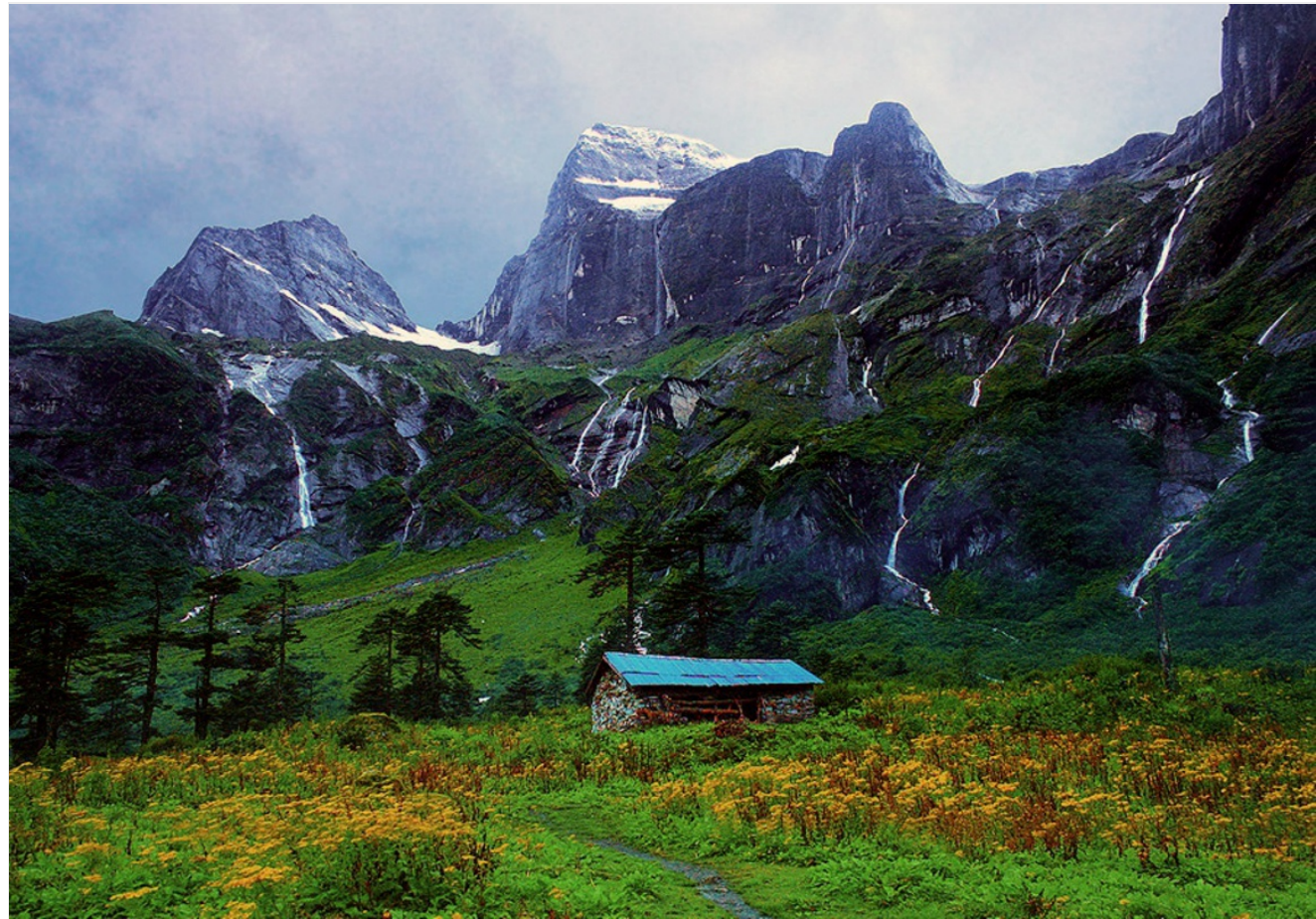

Dhilung/Flickr/CC BY-SA 2.0

Forests at high-altitudes in the Himalayas and Tibetan Plateau are at risk of dying off or retreating downslope as a result of climate change, threatening the region's rich biodiversity, researchers warn. "This is in contrast to the situation in other mountains, such as the Alps" where most long-term ecological studies have been based, says Achim Bräuning, a climate scientist at the University of ErlangenNuremberg, Germany.

A main conclusion coming out of Alpine research is that forest growth at high elevations - especially timberline species that thrive at the transitional zone between woodlands and alpine tundra — is primarily limited by temperature. In a warming world, therefore, "one would expect timberlines to move uphill, as is happening in European mountains," Bräuning says.

"But things appear to be different in the Himalayas and Tibetan Plateau," said Liang Eryuan, an ecologist at the Chinese Academy of Sciences' Institute of Tibetan Plateau Research in Beijing, in a talk at the fifth Third Pole Environment Workshop held in Berlin last month. Liang's team found that the treeline position at several sampling sites in Nepal and southeastern Tibet has not changed in the past 200 years despite the fact that temperatures in the region have risen by $0.4{ }^{\circ} \mathrm{C}$ per decade in the past 50 years - twice the global average and the warmest period in the past 1,000 years. Moreover, many forest stands of Qinghai spruce (Picea crassifolia) a conifer species that grows only in China and is a dominant treeline species in northern Tibetan Plateau — are either dying off or shifting to lower altitudes, Liang says.

SCIENTIFIC To understand why forests in high-mountain Asia behave so differently from the Alps, several AMERTCA ${ }^{\text {TM }}$ research groups roamed the lofty terrains in search of ancient trees, whose annual tree rings provide More from Scientific American. valuable archives of how the plants responded to a changing climate. Liang and colleagues found that the occurrence of "missing tree rings" - an indication of a bad year with little growth — has been increasingly frequent in the past decades in the Himalayan birch (Betula utilis), which forms the Northern Hemisphere's highest treeline at around 4,600 metres above sea level. "This seems to coincide with exceptionally warm and dry spring," Liang says. "This 
pre-monsoon season is particularly crucial for tree growth, and appears to set the tone for the rest of the year."

The situation is much worse in the northern Tibetan Plateau. "The Qinghai spruce simply got pushed off the edge after a few consecutive dry spells, suggesting that the ecosystem is approaching a tipping point," Liang says. The researchers conclude that the growth of treeline species in the Himalayas and the Tibetan Plateau is largely controlled by precipitation — rather than temperature as in the Alps. Many researchers, like Volker Mosbrugger, director of the Senckenberg Research Institute and Natural History Museum in Frankfurt, say, "The findings are surprising because the region is getting wetter overall as a result of global warming" — with precipitation rising by about $12 \%$ since 1960 .

An uneven distribution of that increased precipitation — both spatially and seasonally — could explain some of the results, notes Bräuning, who was not involved in the study. And reduced spring melts, due to glacial retreats and dwindling snowfall, may have exacerbated the impact of pre-monsoonal droughts. "But the total amount of precipitation is just part of the story," he adds.

In a five-year project funded by the German Research Foundation (DFG) headquartered in Bonn, Bräuning and colleagues were able to reconstruct relative humidity and how fast trees "sweat" by transpiration in the Himalayas and Tibetan Plateau at up to 4,450 metres above sea level. The researchers used a method based on measuring oxygen isotopes in tree rings and found that relative humidity at multiple sites across the region has dipped sharply in the past 200 years. Since the 1980 s the rate of transpiration — which depends on temperature, humidity, wind and solar radiation — has increased steadily, especially in areas with reported dying of trees.

"People often forget that the Himalayas and Tibetan Plateau are a lot higher and drier than the Alps," Bräuning says. And climate change at such extreme altitudes can take on a peculiar form. For instance, researchers have long noted that in the region a location's rate of warming is faster the higher in altitude it is; records from high-elevation weather stations also suggest that the loftier terrains are getting less snow and rain despite an overall trend of increased precipitation across the region. The combination, he says, could explain a reduction in humidity — which, together with exposure to strong winds and intense solar radiation, conspires to put highmountain forests under increasing moisture stress. He cautions, however, against making sweeping claims because of possible regional variations.

"The new findings have important implications for forest management," Mosbrugger says. The density of trees, for instance, should be properly controlled so they could be more resistant to droughts. Moreover, there should be efforts to help regenerate the aging forests by reducing the grazing of seedlings by livestock. Such measures are crucial for safeguarding forest ecosystems in the Himalayas and Tibetan Plateau, especially protecting endemic and endangered species at high elevations, he adds.

Image licensed under Creative Commons.

Nature | doi:10.1038/nature.2015.16806 